\title{
End-of-Life Care for a Man with Developmental Disabilities
}

\author{
Ghan-Shyam Lohiya, MD, MS, Lilia Tan-Figueroa, MD, and Francis M. Crinella, PhD
}

Background: Science can artificially maintain many essential life functions. Does such care prolong life or dying?

Methods: A case is described of a patient with developmental disability with unknown health care choices who was hospitalized for drug-resistant urosepsis. He developed aspiration pneumonia, deep vein thrombosis, and respiratory arrest. He required gastrostomy, tracheostomy, artificial ventilation, parenteral nutrition, hemodialysis, multiple anti-infective agents, and blood transfusions. On day 58, a bioethics committee recommended against cardiopulmonary resuscitation. On day 66, the patient's conservator concurred but required continuation of artificial ventilation. To the dismay of some caretakers, the patient continued to receive intrusive care until his death on day 104. The hospital charge was $\$ 709,206$.

Results and Conclusion: Hospital care of patients with mental incapacity can be clinically and ethically challenging. End-of-life decisions can be facilitated when the patient's legal representative and physician actively advocate the patient's best interests and communicate frequently and openly. Suggestions are made for such exigencies. (J Am Board Fam Pract 2003;16:58-62.)

US code (Title 42, chapter 75, subchapter 1 , section 6001(5[1] 1992) defines a developmental disability as a severe and chronic disability that becomes manifest before the person's 22nd birthday (18th in California) and is due to mental retardation, epilepsy, cerebral palsy, autism, or a similar condition. Such disability affects more than 7 million Americans and forces 50,000 of them to live in residential centers for persons with developmental disabilities. ${ }^{1}$ Many such residents have other severe disabilities (dysphagia, contractures, quadriplegia, kyphoscoliosis, recurrent respiratory tract or urinary tract infections, and defects of speech, vision, or hearing). Modern medical and nursing care have increased their lifespan by managing many previously fatal acute illnesses and by maintaining essen-

Submitted, revised, 1 October 2002

From the Fairview Developmental Center (GSL, LTF), Cost Mesa, Calif, and the Department of Pediatrics (GSL, FMC), University of California, Irvine. Address reprint requests to Ghan-Shyam Lohiya, MD, Fairview Developmental Center, 2501 Harbor Boulevard, Costa Mesa, CA 92626.

This study was funded by the State of California (Department of Developmental Services, and Fairview Developmental Center, Costa Mesa, Calif). Opinions expressed herein are those of the authors only. This case was presented at the Fifth Quarterly Grand Rounds at Fairview Developmental Center on 23 July 1999. tial life processes through long-term dialysis, gastrostomy, nephrostomy, or tracheostomy. ${ }^{2,3}$

Some seriously ill residents receive an entire spectrum of intrusive, life-sustaining care before finally dying, often to the dismay of their physicians and caretakers. ${ }^{2,3}$ For ordinary Americans, potentially harmful and futile care can be withheld or withdrawn according to advance directives ${ }^{4}$ or a surrogate's substitute judgment reflecting the patients' premorbid wishes. Most residents of centers for persons with developmental disabilities, however, are unable to exercise this right because of their limited mental incapacity to make an informed end-of-life decision. Substituted judgments cannot be made for them, because they might have never expressed any values or preferences., ${ }^{2,3}$ They can find themselves at the mercy of medical, legal, and administrative bureaucracies, which often default in favor of aggressive treatment. We illustrate these complex issues and suggest practical ways to improve the decision-making process.

\section{Case Report}

A 30-year-old man with Lesch Nyhan syndrome, an $\mathrm{X}$-chromosome-linked recessive disorder, lived for 28 years in a residential center for persons with developmental disabilities. He had moderate mental 
retardation and recurrent nephrolithiasis (requiring lithotripsies and nephrostomies), compulsive selfmutilation, spastic quadriplegia, choreoathetosis, scoliosis, and anemia. He received phenobarbital and valproic acid for tonic-clonic epilepsy, and allopurinol for hyperuricemia (resulting from an absence of hypoxanthine phosphoribosyltransferase). He could not stand. He required assistance with most activities of daily living. He recognized people, verbalized his needs, expressed emotions, fed himself, and enjoyed television.

He was hospitalized for urosepsis caused by a multidrug-resistant Pseudomonas aeruginosa infection and was given intravenous antibiotics in the intensive care unit. When he became dysphagic, a nasogastric feeding tube was inserted. An indwelling urinary catheter was then required to manage urinary retention. On day 12 , he developed deep vein thrombosis in his leg, which was treated with anticoagulants. On day 19, he aspirated and had bronchoscopy. Supervening pneumonia resulting from an infection caused by methicillin-resistant Staphylococcus aureus required treatment with vancomycin, but the vancomycin had to be discontinued because he developed a generalized purpuric rash. On day 26, an indwelling central venous catheter was placed so he could be fed parenterally. On day 39, a gastrostomy (later converted to a jejunostomy) was performed.

On day 53, he stopped breathing and required endotracheal intubation and artificial ventilation. On day 54, he required hemodialysis for renal failure. On day 68 he had a permanent tracheostomy. The patient continuously received one or more anti-infective agents (ceftazidime, tobramycin, piperacillin, clindamycin, fluconazole, sulfamethoxazole-trimethoprim, metronidazole, rifampin, levofloxacin, cefuroxime, vancomycin, imipenem, ampicillin-sulbactam), transfusions of packed red blood cells for severe anemia as a result of bone marrow hypoplasia (hematocrit 15\%, normal = $37 \%$ to $45 \%$ ), and intravenous albumin for anasarca and hypoproteinemia. He frequently tried to remove various invasive tubes and required restraints.

The patient was mentally incapable of preparing an advance health care directive, ${ }^{4}$ and he had never expressed a preference about end-of-life care or religion. Around day 40, his only known relative (a co-resident, 34-year-old brother with LeschNyhan syndrome) commented, "No more! Let him go to God." Some caregivers felt helpless when confronted with the patient's progressive decline and the relentless succession of medical interventions. They wanted the ventilator withdrawn and requested an ethics review.

On day 58, applying the best interests (what a reasonable person would do under the circumstances) doctrine, the ethics committee at the center recommended the following: "if there is respiratory or cardiac arrest, use no emergency cardiopulmonary resuscitation or advanced cardiac life support; use all measures to maintain basic nutrition, hydration, and comfort." The ethics committee of the hospital concurred. This directive was communicated to the State Office of Legal Affairs, and the Regional Center of Orange County (legal conservator). On day 66, they concurred but required continued ventilator support when needed. No further ethics review took place.

On many occasions the patient seemed close to death, but his condition improved, only to deteriorate later. On day 100, he became comatose and hypotensive. An intravenous dopamine drip was started to sustain tissue perfusion, but his blood pressure progressively decreased. On day 103 , the conservator contacted the Director of the Department of Developmental Services for permission to discontinue ventilator support. The patient died on day 104, before receipt of their decision. An autopsy described severe bilateral bronchopneumonia and pyelonephritis as the causes of death.

Caregivers kept a 24-hour vigil during his last 2 days. Because no litigation occurred, a guardian ad litem was not appointed; the conservator had full decision-making authority. The hospital charge, exclusive of physicians' professional fees, totaled $\$ 709,206$ (mean $\$ 6,819 /$ d). Some illustrative charges are listed in Table 1 . Cost never became an issue because all bills were paid by Medicaid.

\section{Discussion}

This report highlights four critical issues for family physicians. First, end-of-life decisions for persons with developmental disabilities should be timely and comprehensive. Second, there are real-life difficulties in making a decision to withhold or withdraw care for a mentally incapable person who is relatively young, has no dedicated family advocate, is under the guardianship of a state conservator, is not in a persistent vegetative state, has no fatal 
Table 1. Hospital Charges: Summary by Department and Sample Charges for Selected Services

\begin{tabular}{lr}
\hline Service & $\begin{array}{r}\text { Hospital } \\
\text { Charge, \$ }\end{array}$ \\
\hline Departmental summary & \\
Room, 104 days & 171,146 \\
Pharmacy & 227,092 \\
Supplies & 94,399 \\
Laboratory & 75,655 \\
Respiratory services & 53,796 \\
Radiology & 21,327 \\
Hemodialysis & 29,160 \\
Other & 36,631 \\
Grand total & 709,206 \\
Sample charge per service & \\
Room, medical floor per day & 674 \\
Room, intensive care unit per day & 1,749 \\
Lorazepam, 2-mg injection & 348 \\
Clindamycin, 600-mg injection & 603 \\
Urine culture, sensitivity & 250 \\
Complete blood count & 126 \\
Basic metabolic panel, 7 tests & 245 \\
Blood type, cross-match & 450 \\
Packed red blood cells, 1 U & 102 \\
Chest radiograph, portable & 391 \\
Arterial blood gases & 548 \\
Ventilator per day & \\
Oxygen per day & \\
\hline & \\
&
\end{tabular}

disease such as terminal cancer, whose condition waxes and wanes, and whose end-of-life preferences are unknown. Third, care of nonverbal persons with severe chronic developmental, neurologic, and orthopedic disabilities is complex and requires extreme vigilance. Finally, serious complications can supervene in a patient hospitalized for a seemingly curable condition, which makes a case for humility in this era of ever-increasing reliance on medical gadgetry.

Did our patient receive futile care? Some define futile care as that which fails to correct the underlying fatal disease or condition and might actually harm or result in insult to the patient. This situation has been eloquently expressed by McKnight and Bellis as "science's constantly increasing power can keep the human body alive for longer than any reasonable person would want to inhabit it." ${ }^{2}$ Of course, this position has to be balanced with physicians' imprecision in prognosticating death. Many residential center patients with multiple severe disabilities (gastrostomy, tracheostomy, cerebral palsy, scoliosis, quadriplegia) live for decades and survive critical illnesses (aspiration pneumonia requiring artificial ventilation). Prognosis for some conditions, such as pneumonia, carries far more uncertainty than for others, such as for metastatic cancer. ${ }^{5}$ Thus, it is difficult to assign an absolute definition to futile care, which is inherently a valueladen determination. ${ }^{6}$

When should we withhold or withdraw treatment? Multiple organ system failure is considered to be an indication to withhold care. This indication, however, is merely a line in the sand, because respiratory failure can be temporized by artificial ventilation, vasopressors can help maintain perfusion, and so on. There is no managed-care-type algorithm or right-wrong option that can be uniformly applied to all cases. We are forced to deal with this issue on a case-by-case basis, sometimes daily for weeks, and then select the least ethically objectionable choice from many available suboptimal options. Hindsight might prove us wrong, but satisfaction and justice will be derived in following the process!

For our patient, the ethics review was late (on day 58 of his terminal illness), not comprehensive (in reference to tube feeding, ventilator, tracheostomy, antibiotics, hemodialysis, parenteral nutrition, or transfusion), and without further updates (in the face of numerous complications). Although some caretakers wanted care withheld, none requested a formal bioethics update, perhaps out of ignorance. The conservator, a public agency, probably wanted review at the highest hierarchal level to forestall a rash decision. The outcome or the decision could be potentially irreversible-death, and the state might be criticized for letting a helpless person die prematurely to conserve resources. ${ }^{3} \mathrm{Lo}-$ gistically, this process entails delay and can prolong the dying patient's suffering.

Relevant in this context is a supreme court ruling curbing a conservator's right to remove life support from a conscious patient without a clear and convincing proof of the patient's wish, because "the decision to treat is reversible, but the decision to withdraw treatment is not." " Moreover, the state grants statutory immunity from liability for damages to physicians who refuse to withdraw lifesustaining services. ${ }^{8}$ Nevertheless, medical opinion is what counts the most to determine the patients best interests. Ideally, the hospitalist, having the most knowledge about the patient's treatment and 
prognosis, should be the one to initiate and navigate the end-of-life decision process. Good end-oflife decisions can emerge only if the hospitalist overcomes personal biases, evaluates the patient as a whole human being rather than by numbers (vital signs, laboratory parameters), and renders timely, honest, and definitive opinions.

Although residents of centers for persons with developmental disabilities have no right to refuse treatment, they do have a right to appropriate medical decisions made on their behalf. ${ }^{2}$ Life-sustaining treatment need not be provided at all times, because to do so might entail keeping friendless debilitated persons on life support when no one is entrusted to make the choice to stop. ${ }^{3}$ Unfortunately, there is no objective instrument to measure a resident's quality of life. Existing instruments, ${ }^{9}$ based on activities of daily living and cognition, are unsuitable for residents with preexisting mental incapacity. Quality-of-life assessments should be supplemented by such factors as duration of hospitalization and life-sustaining care, symptoms (pain, dyspnea, discomfort), and caretaker opinion scores of the resident's best interest and global well-being.

Residents should be enabled to exercise their rights of self-determination ${ }^{4}$ as an integral part of routine care. ${ }^{10}$ End-of-life decisions should be made proactively rather than reactively or belatedly. The attending physician should clinically assess each resident's mental capacity, including capacity when assisted by family. ${ }^{3}$ Residents who cannot make an advance health care decision, but who can sign a power of attorney for health care should be encouraged to do so. ${ }^{10}$ Psychiatric conditions interfering with decision-making capacity should be treated. ${ }^{3}$ Residents' expressed wishes and subtle cues (new-onset gestures toward the sky, spontaneous utterances, pulling of medical tubes) should be documented; these gestures might be the nonverbal resident's only voice. ${ }^{2,3}$

The physician should establish a treatment goal (restorative, supportive, or palliative) and update it annually, during hospitalization, and as needed. ${ }^{10}$ Institution bioethics committees should promptly review all cases slated for palliative (comfort) care, considering the resident's best interest (patient autonomy, nonmaleficence, beneficence, and medical integrity). ${ }^{10}$ Specific life-sustaining procedures should be considered individually. Medical resources are limited and should not be spent reflexively. For all residents receiving palliative care, a do-not-resuscitate form should be completed to instruct emergency medical personnel to forgo prehospital resuscitation. ${ }^{10}$ Pain should be controlled effectively. $^{11}$

Our patient's hospitalization interrupted his long-term relationship with his usual physician and caretakers, who were full-time employees of the residential center. Ideally, the primary care physician should hospitalize the patient and be the decision maker. Doing so, however, necessitates hospital privileges (entailing annual dues, professional liability insurance, minimum case census, and meeting attendance) and time commitment for a single patient's care in an off-campus hospital. To maintain continuity of care, the next best option is for the primary care physician to maintain daily communication with the hospitalist and to visit the hospitalized patient as needed. It might be desirable to have a preferred hospitalist panel that is familiar with the residents' special needs, as well as a hospital with an ideologically receptive management. Ideally the hospitalist, having the most knowledge about the patient's treatment and prognosis, should be the one to actively initiate and navigate the end-of-life-decision process.

The proxy decision-maker hierarchy (in descending order) has been formalized for our residents: attorney in fact, conservator, spouse, child, parent, sibling, other family, the regional center director, and lastly, the developmental center medical director (policy memo \#118 of 7 February 2002, Gary W. Scott, Acting Deputy Director, Department of Developmental Services). The entire treatment team should be educated about end-oflife care, and legal myths should be dispelled. ${ }^{12}$

The hospital charge was substantial (Table 1). There might be room for cutting cost without cutting quality. The cost of most consumer items is competitively restrained by presale price disclosure. In health care, however, neither the patient (who might not be able to compare value) nor his agent (physician) is informed beforehand about the cost of services. If a supermarket can put a price tag on thousands of relatively inexpensive items, can a hospital do the same for various supplies, tests, and drugs? Various hospital departments with high charges could team up to educate physicians on cost-efficiency, waste avoidance, and care coordination. Hospitals could emulate the price categorization used by managed care formularies. These issues merit serious investigation in this era of great 
societal concern about skyrocketing health care costs. ${ }^{13}$

Should our patient have been subjected to such medical heroics at such an enormous cost? Could not nature, left to itself, have abbreviated his suffering? Did our patient have a duty to die because of the cost and burden of his care? These questions evaporate the moment we rid ourselves of our biases. A developmental disability is not an indication to shorten life. A willingness to die for society is a charitable act rather than a moral requirement. Our patient had no duty to die unless it was for his own welfare (relief from suffering caused by a terminal illness). The United States can afford expensive care for its citizens; therefore, cost alone is a moot issue. $^{2}$ For reference, the mean cost of caring for a resident in our center is $\$ 135,000$ a year. The severity or nature of the disability is also irrelevant, because any discrimination would lead the selfproclaimed superior majority to try to rid itself of those it deems undesirable (wrong age, race, religion, political belief, sexual preference, employment, and looks). ${ }^{2,3}$

About 500 вс, Plato proclaimed that good clinical medicine requires a marriage of scientific knowledge and humane care. This recipe remains the all-time universal prescription for good end-oflife care!

Quang Nguyen, MD, Donna Rodriguez, and Arleen Downing, MD, provided medical records, Debbie Butler contributed research assistance, Suzanne Donovan provided administrative help, and Barbara Rycroft provided library support.

\section{References}

1. Association of Retarded Citizens. Introduction to mental retardation. Available at http://thearc.org/ faqs/mrqa.html. Accessed 14 October 2001.

2. McKnight DK, Bellis M. Foregoing life-sustaining treatment for adult, developmentally disabled public wards: a proposed statute. Am J Law Med 1992;18: 203-32.

3. Friedman RI. Use of advance directives: facilitating health care decisions by adults with mental retardation and their families. Ment Retard 1998;36: 444-56.

4. Patient Self-determination Act. Sect 4206,4751,104, Stat 1388,1388-115,1388-204; 42 USC 1395cc(f), Medicare, 1396a(w) Medicaid. Omnibus Budget Reconciliation Act of 1990: HR 5835, Public Law 101-508, 101st Congress. Baltimore, Md: Department of Health and Human Services, Social Security Administration, Office of Legislation and Congressional Affairs, 1993.

5. Christakis NA, Lamont EB. Extent and determinants of error in doctors' prognoses in terminally ill patients: prospective cohort study. BMJ 2000;320: 469-72.

6. Medical futility in end-of-life care: report of the Council on Ethical and Judicial Affairs. JAMA 1999; 281:937-41.

7. Ruling curbs removal of life support. Los Angeles Times 10 August 2001: A1, A29.

8. Addlestone SI. Liability for improper maintenance of life support: balancing patient and physician autonomy. Vanderbilt Law Rev 1993;46:1255-81.

9. 1993 National Mortality Followback Survey. National Center for Health Statistics. Hyattsville, Md: US Department of Health and Human Services, Public Health Service, Centers for Disease Control, 1998.

10. Extreme care, humane options. ECHO nursing facility recommendations. Carmichael, Calif: Sacramento Healthcare Decisions, 2000:1-28.

11. Glajchen M. Chronic pain: treatment barriers and strategies for clinical practice. J Am Board Fam Pract 2001;14:211-8.

12. Meisel A, Snyder L, Quill T. Seven legal barriers to end-of-life care: myths, realities, and grains of truth. JAMA 2000;284:2495-501.

13. Young DW, McCarthy SM, Barrett D, Kenagy JW, Pinakiewicz DC. Beyond health care cost containment: creating collaborative arrangements among the stakeholders. Int J Health Plann Manage 2001; 16:207-28. 